\title{
Determinants of bird conservation action implementation and associated population trends of threatened species
}

Luther, David A.; Brooks, Thomas M.; Butchart, Stuart H. M.; Hayward, Matthew; Kester, Marieke E. ; Lamoreux, John; Upgren, Amy

\section{Conservation Biology}

DOI:

10.1111/cobi. 12757

Published: 01/12/2016

Peer reviewed version

Cyswllt i'r cyhoeddiad / Link to publication

Dyfyniad o'r fersiwn a gyhoeddwyd / Citation for published version (APA):

Luther, D. A., Brooks, T. M., Butchart, S. H. M., Hayward, M., Kester, M. E., Lamoreux, J., \& Upgren, A. (2016). Determinants of bird conservation action implementation and associated population trends of threatened species. Conservation Biology, 30(6), 1338-1346.

https://doi.org/10.1111/cobi.12757

Hawliau Cyffredinol / General rights

Copyright and moral rights for the publications made accessible in the public portal are retained by the authors and/or other copyright owners and it is a condition of accessing publications that users recognise and abide by the legal requirements associated with these rights.

- Users may download and print one copy of any publication from the public portal for the purpose of private study or research.

- You may not further distribute the material or use it for any profit-making activity or commercial gain

- You may freely distribute the URL identifying the publication in the public portal ?

Take down policy

If you believe that this document breaches copyright please contact us providing details, and we will remove access to the work immediately and investigate your claim. 
1 Title

2 Determinants of bird conservation action implementation and associated

3 population trends of threatened species

4 Short Running Title - avian conservation actions

5 Authors

6 David A. Luther - George Mason University, dluther@gmu.edu

7 Thomas M. Brooks - International Union for Conservation of Nature,

8 Thomas.brooks@iucn.org

9 Stuart H. M. Butchart - BirdLife International, Stuart.Butchart@birdlife.org

10 Matt W. Hayward -Bangor University, m.hayward@bangor.ac.uk

11 Marieke E. Kester - George Mason University, mkester2@gmu.edu

12 John Lamoreux - National Fish and Wildlife Foundation, John.Lamoreux@nfwf.org

13 Amy Upgren - George Mason University, aupgren@yahoo.com

\section{Statement of authorship}

15 DL, TB, SB, MH, JL, AU designed the study. SB provided the data. MK performed 16 modeling work and analyzed output data. DL wrote the first draft of the manuscript 17 and all authors contributed substantially to revisions.

18 Keywords - IUCN redlist, conservation actions, extinction risk, birds

19 Abstract 173 words; Main text 3,484 words; Reference 51; Figures 2; Tables 2

20 Corresponding author -David A. Luther George Mason University, 4400 University

21 Dr., MS 3E1, Fairfax VA 22030 Phone: 703-993-5267 Email: dluther@gmu.edu

\section{Abstract}


1 Conservation actions, such as habitat protection, attempt to halt the loss of

2 threatened species and help their populations to recover. Thus far, research has

3 examined the efficiency and the effectiveness of actions individually, yet;

4 conservation actions generally occur simultaneously so the full suite of

5 implemented conservation actions should be consideredassessed. We used the

6 conservation actions associated with the threatened birds of the world (IUCN Red

7 List) to assess which biological factors-(related to taxonomy and ecology) and

8 anthropogenic factors (related to geo-economics and population trends) are

9 associated with the implementation of different classes of conservation actions. We

10 also assessed which conservation actions are associated with increasing population

11 trends. Threat category, taxonomic order, and geo-economic variables were the

12 strongest predictors of implemented hich-conservation actions were

13 implemented. Species with invasive alien species control/eradication, ex-situ

14 conservation, international legislation, reintroduction, or education and awareness-

15 raising were more likely to have increasing populations. I'd add a sentence in listing

16 the less effective actions. These results illustrate the importance of developing a

17 predictive science of conservation actions and the relative efficiencies of each class

18 of implemented conservation action for threatened and near-threatened birds

19 around the world. 


\section{Introduction}

3 Due to human activities, the rate of species extinction is higher now than at any

4 other time in the past 65 million years (Barnosky et al 2011, Pimm et al 2014).

5 Conservation efforts aim to slow-down, stop, and reverse threats to species and thus

6 the current loss of biodiversity. However, the extinction risk to species continues to

7 rise (CBD 2014-). This does not mean conservation efforts have failed. Indeed,

8 conservation efforts have circumvented at least $20 \%$ of projected increases in

9 aggregate extinction risk to birds and mammals over the last four decades, as measured by changes in the IUCN Red List of Threatened Species (hereafter, "Red List") (Hoffmann et al 2010). For ungulates, increases in aggregate extinction risk since 1996 would have been eight times greater in the absence of conservation action (Hoffmann et al 2015). example, between 1994 and 2004, conservation efforts likely prevented at least 16 bird species from going extinct (Butchart et al 2006, Rodrigues 2006). The implementation of conservation actions for threatened species is critical if we are to support the recovery of currently threatened species, as agreed in Aichi Target 12 of the 2010-2020 Strategic Plan for Biodiversity (https://www.cbd.int/sp/targets/) and prevent more species from declining and going extinct.

Research on the suite of parameters that affect extinction risk for threatened species, including biological and geo-economic factors and threats, has made great progress toward predicting extinction risk (Bland et al 2014, Cardillo et al 2006, 
1 2008, Davidson et al 2009, Davies et al 2006, Fisher and Owens 2004, Mace 2004,

2 Owens and Bennett 2000, Purvis et al 2000). While these studies have been

3 remarkably informative about the extinction risk and threats facing species, it is

4 only through the implementation of conservation actions that we have a chance to

5 improve the status of threatened species. Thus, just as there currently is a predictive

6 science of extinction risk, there is a need for a predictive science of conservation

7 actions, which would illuminate how, why, and where conservation actions are best

$8 \quad$ implemented for threatened species and assess their efficiency.

9 Such a predictive science of conservation actions has not been completely

10 overlooked. Hayward (2011) used a subsample of 144 threatened mammals from

11 the Red List that improved or declined in status between 2004 and 2008

12 assessments to assess the link between threats, conservation actions, and

13 population trends. Brooks et al (2009) focused on the suite of conservation actions

14 implemented in tropical rainforests to examine their effectiveness. Chapman (2014)

15 surveyed experts about conservation actions as to whether they thought the actions

16 were successful. Finally and most comprehensively, Williams et al (2012) conducted

17 a literature review that assessed the efficiencies of each of the IUCN conservation

18 action categories for birds. Building off of these attempts to assess the efficiency and

19 effectiveness of implemented conservation actions, we assess the biological and geo-

20 economic parameters that influence conservation action implementation and are

21 associated with increasing population trends, using data for birds from the Red List.

22 Here, we assess which factors predict implementation of conservation

23 actions, and examine which actions are associated with different directions of 
1 population trends for threatened and Near Threatened bird species (i.e. in the

2 categories of Critically Endangered, Endangered or Vulnerable).

3

4

5 We examined the conservation actions underway for species assessed by BirdLife International as threatened (i.e., Critically Endangered, Endangered or Vulnerable) or Near Threatened on the Red List (BirdLife International IUCN red List for birds 2014 http://www.birdlife.org on May 27 2014). We excluded those Critically

\section{Endangered species tagged as Possibly Extinct (PE) because most such species} require targeted searches to rediscover any surviving individuals before the most appropriate conservation actions can be determined.

Birds are an excellent study group to investigate such questions, because all birds have been comprehensively assessed against the Red List Categories and Criteria (IUCN 2012), revealing 1,373 species to be threatened and 959 to be Near Threatened; i.e., $22 \%$ of the world's 10,425 bird species are considered of elevated conservation concern (BirdLife International 2014). Further, 145 species are assessed as recently Extinct, Extinct in the Wild, or Critically Endangered (Possibly Extinct) (1\% of all bird species) and only 62 are Data Deficient $(0.5 \%$ of all bird species). Moreover, bird populations occur in most habitats and all countries worldwide, they are easily identifiable, practical to monitor and research, and there are large networks of people studying birds, compiling information about them and implementing conservation actions for them (Brooks et al 2008). 
We used data on conservation actions underway as documented in the

2 Species Information Service, the database co-managed by IUCN and BirdLife

3 International, which underpins the Red List. The fields for conservation actions

4 underway largely represent a subset of the actions in the classification scheme

5 developed by Salafsky et al (2008), and relate to a subset of those actions for which

6 meaningful data can be compiled for the majority of species on the Red List (see

7 Table 1). Conservation actions included in the database represent those that are

8 ongoing or took place within the last decade. One conservation action we excluded

9 was the identification of 'important sites' for species. Because nearly all (>95\%) of threatened and Near Threatened bird species have Important Bird and Biodiversity

11 Areas (IBAs) identified for them (BirdLife International 2014b), this parameter would have little explanatory power in our analysis. We examined both biological and anthropogenic factors as independent predictor variables of conservation action implementation (see Table 1). We also included monitoring which is not technically a conservation action according to Salafsky et al (2008) but is instead a research need, yet tends to be a critical component in terms of assessing population trends as related to conservation actions. All biological data were extracted from the

18 Species Information Service in July 2012

(http://www.birdlife.org/datazone/species).

21 'level 1' classes (http://www.iucnredlist.org/technical-documents/classificationschemes/habitats-classification-scheme-ver3) coded as being of major importance during the breeding season. To simplify the analyses, we summed the four marine 
1 habitat subcategories, neritic, intertidal, marine coastal and oceanic, to create a

2 more general "marine" category (which included 107 species), and pooled the

3 categories for caves and rocky areas, introduced vegetation and artificial

4 terrestrial/aquatic habitats, other habitats, and unknown habitats into a class we

5 termed "other" (which included 142 species). Species that inhabit multiple

6 geographic realms were scored in a "multiple" category, we scored species in

7 multiple landmass types in a "multiple" category as well.

8

9

Geo-economic factors, which describe the economic development of the places where species live, can be an important determinant of conservation implementation. To calculate the per capita area-weighted Gross Domestic Product (GDP) for a species, we averaged the GDP for all countries in which each species occurs relative to the portion of its range within each country (Rodrigues et al 2014). The GDP is calculated as per capita in 1990 international Geary-Khamis dollars. GDP data are from the World Economic Outlook by the International Monitary Fund (2014 dataset): http://www.imf.org/external/data.htm. One hundred and eighty-eight countries belong to the IMF. For the few that do not belong to it, we used estimates of GDP from the CIA Factbook (accessed 21 Feb 2015; see SOM for a list of countries):

https://www.cia.gov/library/publications/the-world-factbook/fields/2004.html. Binomial regression models were fit to explain the presence of conservation actions for 2,177 bird species. Missing data, among 4 variables with between $0.05 \%$ 
1 and 5.9\% missing (see SOM for details of missing data), were singly imputed (Figure $21)$

Best models were selected using a combination of the Akaike Information

4 Criterion (AIC) and an assessment of the generalized variance inflation factor to

5 ensure low collinearity among predictors. Collinearity among predictors was judged

6 acceptable when the generalized variance inflation factor was below $\sqrt{3}$ (Zuur et al

7 2010). If the generalized inflation factor was $>\sqrt{3}$, that model was not considered

8 valid. After a final model was selected, Pearson residuals were binned and examined

9 to ensure no patterns emerged that would suggest an important predictor was left

10 out of the model. Residuals were plotted against all predictor variables, both those

11 included and excluded from the model, to ensure important predictors had not been

removed. Model averaging was conducted on the best models so that the cumulative Akaike weight $\geq 0.95$ (Johnson and Omland 2004) for each of the nine conservation actions, resulting in one average final model for each conservation action. The best models used for averaging are reported (Supplemental Online Material Table 1) along with the averaged parameter estimate, unconditional standard error, and confidence intervals (Supplemental Online Material Table 2). To determine the importance of variables we calculated the $90 \%$ (estimate $\pm 1.64 \mathrm{SE}$ ) and $95 \%$ (estimate $\pm 1.96 \mathrm{SE})$ confidence intervals around the model averaged parameter estimates (Kittle et al., 2008; Mazerolle 2004). If the confidence interval does not

21 contain 0 we can conclude that the parameter has an effect on the dependent 22 variable (i.e. the estimate is different from 0 ). 
Using linear regression, the relationship between predictor variables and the number of conservation actions was analyzed.

Finally, a binomial regression model was fitted (using AIC and the generalized variance inflation factor as detailed above) to explore which conservation actions were associated with an increasing versus decreasing population trend for threatened and Near Threatened bird species. Population trends are based on ongoing trend data over the last several years. Coefficients for binomial regression were interpreted as the odds ratio using the antilog of the raw coefficients. Numerical results are reported as mean \pm SEM. All tests were conducted using R statistical software, ver. 3.0.2, R Core Team 2014.

\section{Results}

\section{Number and Class of Implemented Conservation Actions}

In total, 5,424 conservation actions are documented as being implemented for the 2,177 threatened and Near Threatened bird species on the Red List, with a mean of $2.55 \pm 0.028$ conservation actions per species. The most frequent conservation action implemented was for a protected area to cover a population of the species (74\% of species). International trade regulations and action plans exist for $23 \%$ and $18 \%$ of species, respectively. Other conservation actions were implemented for $<10 \%$ of species. Predictive models for the conservation actions, international trade regulations, international legislation, invasive species control, and action plans, all had relatively high weighted-explained deviance, $0.68,0.59$, 0.55 and 0.54 , respectively. Predictive models for other conservation actions, Ex Situ 
1

conservation, monitoring, reintroduction, education and population protection didn't explain the deviance as well, $0.38,0.35,0.29,0.21,0.2$, respectively. Red List category was the most important predictor for conservation action implementation. More severely threatened species were more likely to be targeted by more conservation actions, with Critically Endangered and Endangered species having significantly more conservation actions than Vulnerable and Near

Threatened species $\left(\mathrm{F}_{3,2173}=45.56, \mathrm{P}<0.001\right)$.

Species that live in Europe or multiple regions had the most conservation actions implemented, while species in West and Central Asia, North Africa, and Antarctica had the fewest $\left(\mathrm{F}_{13,2163}=21.69, \mathrm{P}<0.001\right)$. In addition, species that breed in more countries have more conservation actions implemented $\left(\mathrm{F}_{1,2175}=240.4, \mathrm{P}<\right.$ 0.001). For every $1 \%$ increase in the amount area of a species range within G20 or OECD countries, the number of conservation actions increased by 0.00196 and 0.0093 , respectively $\left(\mathrm{F}_{1,2175}=9.54, \mathrm{P}=0.002 ; \mathrm{F}_{1,2175}=148.8, \mathrm{P}<0.001\right)$. As the areaweighted GDP of species increased, so did the likelihood that the species would have conservation actions in place $\left(\mathrm{F}_{1,2175}=81.51, \mathrm{P}<0.001\right)$.

Species' biology was also associated with the implementation of conservation actions. Species with longer generation times were more likely to have more conservation actions. For every year increase in generation length, the number of conservation actions implemented increased by $0.13\left(\mathrm{~F}_{1,2175}=482.6, \mathrm{P}<0.001\right)$. Species that inhabit marine and inland wetland had more conservation actions in place than species in other habitats $\left(\mathrm{F}_{7,2169}=20.28, \mathrm{P}<0.001\right)$. More specifically, species in these habitats tended to have more monitoring, protected areas, invasive 
| 1 alien species control/eradication, ex-situ conservation, and international legislation-.

2 The type of landmass where a species occurred was an important predictor variable

3 for all implemented conservation actions except education and awareness-raising,

4 reintroduction, and ex situ conservation, with more actions implemented for species

$5 \quad$ inhabiting oceanic islands $\left(\mathrm{F}_{3,48}=9.22, \mathrm{P}<0.001\right)$.

6

7 education and awareness-raising, action plans, ex situ conservation, international

8 legislation, and trade control. The taxonomic orders Anseriformes (ducks, geese,

9 and swans), Falconiformes (raptors), Gaviiformes (divers/loons),

10 Phoenicopteriformes (flamingoes), and Psittaciformes (parrots) had the highest

11 numbers of conservation actions while Caprimulgiformes (nightjars),

12 Columbiformes (pigeons), Cuculiformes (cuckoos), Passeriformes (perching birds),

13 and Piciformes (woodpeckers) had the fewest $\left(\mathrm{F}_{23,2153}=21.68, \mathrm{P}<0.001\right)$.

Conservation Actions and Population Trends

Among threatened and Near Threatened bird species, 83\% have decreasing population trends, $3 \%$ increasing, $11 \%$ stable, and $2 \%$ have unknown population trends (BirdLife International 2014). Population trend was a predictor variable in $58 \%$ of the models. Specifically, it was a predictor in all ten best models for ex situ conservation, invasive alien species control/eradication, reintroduction, and international trade controls. Species with increasing populations had more conservation actions in place $(4.01 \pm .185)$ than those with decreasing $(2.51 \pm 0.03)$, stable $(2.47 \pm 0.09)$ or unknown population trends $(0.98 \pm 0.14)\left(\mathrm{F}_{3,2173}=34.31, \mathrm{P}<\right.$ 
1 0.001). The best generalized binomial regression model that explained an increasing

2 or decreasing population trend based on the conservation actions in place included

3 education and awareness-raising, international legislation, reintroduction, ex-situ

4 conservation, and invasive alien species control/eradication (Table 2). Species with

5 these conservation actions showed increased odds of having a positive population

6 trend of 2.16, 2.62, 2.82, 3.09, and 10.63 respectively (Figure 2).

7

\section{Discussion}

9 These results depict both the biological and anthropogenic environment in

10

11

12

which conservation actions are most likely to be implemented and are most likely to be effective. More severely threatened species received more types of conservation actions, presumably because the conservation of more severely threatened species is seen as more urgent, and/or because more threatened species face a wider range of threats. Species with increasing population trends had 1.6 times more conservation actions in place than those with stable or decreasing populations, suggesting that implementation of multiple conservation actions may be more effective in reducing extinction risk. In particular, the implementation of invasive alien species control/eradication, ex-situ conservation, international legislation, reintroduction, and education and awareness-raising were most frequently associated with positive population trends. Knowledge of the circumstances in which conservation actions are implemented as well as which ones are most successful, such as we describe here, could tremendously benefit the future of species conservation with implications for future resource allocation for 
1

conservation actions as well as assessments of the potential success of different types of actions.

Biological factors important in predictive models of biodiversity threats, such as generation length, clutch size, taxonomic group, and habitat type, were also important in all of the best predictive models of conservation action implementation. In particular, generation length was an important predictor for five of the nine conservation action types assessed and is an important predictor in threat models (Owens and Bennett 2000, Fisher and Owens 2004). Many of the biological factors in the models are correlated with taxonomy, and closely related species within taxonomic groups are generally susceptible to similar threats (Gaston and Blackburn 1995, Mace 2004, Owens and Bennett 2000); consequently, they tend to receive similar conservation actions.

Taxonomic order was an important factor associated with education and awareness-raising, action plans, ex situ conservation, international legislation, and trade control, suggesting that these five classes of conservation action tend to be applied in a taxonomically selective way. Species in taxonomic groups that are particularly threatened by over-exploitation, such as Anseriformes, which are threatened by hunting (Green 1996), Psittaciformes, which are threatened by trapping for the pet industry (Collar and Juniper 1992, Wright et al 2001) and Falconiformes, some of which are threatened by trapping for falconry (Butchart et al 2005), receive a disproportionate number of conservation actions compared with species in other orders. Species in these orders tend to be particularly palatable, 
1 colorful, carnivorous, or otherwise charismatic, explaining both their attractiveness

2 for harvest as well as conservation attention (Leader-Williams \& Dublin 2000).

Whether a species lives on an oceanic island, continental island, or continent was an important predictor for six of the nine conservation actions. Being on an oceanic island was a strong predictor of the existence of action plans, international legislation, international trade regulations, and invasive species control/eradication implementation, while species on continents had more monitoring and protected areas. Invasive species have been a leading cause of extinction for native species on islands (Clavero and Garcia-Berthou 2004). However, eradicating invasive species is an increasingly applied and successful conservation tool (Veitch, Clout, and Towns 2011). Our finding that populations of threatened and Near Threatened species are ten times more likely to be increasing when invasive species control/eradication is implemented is a strong signal that this conservation action has a positive impact on such species. With ongoing declines in oceanic seabird populations, international legislation has been strengthened to reduce threats to these species, as they typically cross national borders and often use areas beyond national jurisdiction while foraging or migrating (Croxall et al 2012, Wolf et al 2006). Given the high rates of endemism and endangerment of species on oceanic islands, more protected areas (and their effective management) could help conserve their populations (Kier et al 2009). (McCarthy et al. 2012), which explains the importance of geo-economic factors as predictors of the implementation of many conservation actions. Geo-economic 
1 factors were present in all of the ten best models, except for education and

2 awareness-raising, and species in more economically developed countries are more

3 likely to receive conservation actions. This appears to be consistent with the

4 Kuznets curve, which predicts that there is an hump-shaped relationship between

5 wealth and environmental quality (Mills and Waite 2009), whereby improving

6 population trends for threatened and Near Threatened species coincided with

7 wealthy countries. However, among poor countries, increases in wealth can lead to

8 increased threats, which can create a complex relationship between a country's

9 financial resources and the conservation of biodiversity (Mills and Waite 2009).

10 Another complication with economic predictive variables is that finances often flow

11 across international borders, which can lead to the transfer of funds for

12 conservation efforts as well as the transfer of threats, such as logging and the

13 harvesting of species (Lenzen et al. 2012, Weinzettel et al 2013). However, some of

14 the richest countries have shown poor results with regard to species recovery, while

15 many of the best successes have come from countries with small per capita GDPs

16 (Rodrigues et al 2014), illustrating that finances alone cannot explain the

17 implementation or efficiency of conservation actions.-

18 Reintroduction, ex-situ, invasive alien species control/eradication, education

19 and awareness-raising efforts, and international legislation are all significantly

20 associated with increasing population trends among species of conservation

21 concern. Action plans, monitoring, protected areas, and international trade controls

22 are associated as well, but not significantly. The reasons for these differences are

23 not clear. Certainly, reintroduction and invasive alien species control/eradication 
1 are highly targeted actions, which can often yield dramatic positive results.

2 Conversely, action plans and monitoring are preconditions to other conservation

3 actions and alone are insufficient to ensure population increases (furthermore, the

4 existence of an action plan does not necessarily imply that it is being implemented

5 adequately, or at all). Unfortunately, trade controls can often be ineffective, with

6 illegal trade being a widespread issue for utilized species (Magnin 1991). In

7 addition, some conservation actions might have interactive effects that increase

8 opportunities for population recovery. For example, invasive species eradications

9 coupled with reintroductions might increase the likelihood of population recovery more than one of these conservation actions alone. should increase the future success of conservation efforts. While our models accounted for many of the biological and anthropogenic factors thought to be associated with threats to species and hence potentially with conservation action implementation, additional factors are likely to play a role. Climate change is an important variable that we did not account for; however, all of the conservation actions that we assessed can be implemented in a "climate smart" manner and remain relevant in the presence of climate change (McClanahan et al 2008, Stein et al 2014). Future efforts should also look at the relationship between particular threats and the implementation of conservation actions, specifically to measure the alignment between them and to use that as a predictor for positive population trends. Future research should investigate similar questions in other taxa and refine our results to pinpoint the correlates of successful conservation actions and help 
1 improve the overall effectiveness of conservation action for species of conservation

2 concern.

3

\section{Acknowledgements}

5 We thank the many thousands of individuals and organizations who contribute to

6 BirdLife's extinction risk assessments for species on the Red List, from which the

7 datasets used here are derived. We thank Mike Hoffmann for aiding in the initial

8 coordination of this project.

9

10

11

12 
Barnosky, A.D., et al. (2011). Has the Earth's sixth mass extinction already arrived?

Nature, 471.7336 51-57.

6 BirdLife International (2014). Important Bird and Biodiversity Areas: A global

7 network for conserving nature and benefiting people. Cambridge: BirdLife

8 International. Available at http://www.birdlife.org/datazone/sowb/sowbpubs\#IBA

9 Bland, L. M., Collen, B., Orme, C. D. L., \& Bielby, J. (2015). Predicting the conservation 10 status of data-deficient species. Conservation Biology, 29(1), 250-259.

11 Brooks, T.M., Collar, N.J., Green, R.E., Marsden, S.J. \& Pain, D.J. (2008). The science of 12 bird conservation. Bird Conservation International 18, S2-S12.

13 Brooks, TM and Wright, SJ and Sheil, D. (2009) Evaluating the success of

14 conservation actions in safeguarding tropical forest biodiversity. Conservation

15 Biology, 23, (6), 1448-1457.

16 Butchart, S. H. M., et al. (2005). Using Red List Indices to measure progress towards 17 the 2010 target and beyond. Philosophical Transactions of the Royal Society B:

18 Biological Sciences, 360, 1454, 255-268.

19 Butchart, S. H. M., Stattersfield, A. J. and Collar, N. J. (2006) How many bird 20 extinctions have we prevented? Oryx, 40, 266-278.

21 Cabin, Robert J., and Randall J. Mitchell. (2000). To Bonferroni or not to Bonferroni: 22 when and how are the questions." Bulletin of the Ecological Society of America, 24623248. 
1 Cardillo et al (2006). Latent extinction risk and the future battlegrounds of mammal

2 conservation. PNAS, 103, 4157-4161.

3 Cardillo et al (2008). The predictability of extinction: biological and external

4 correlates of decline in mammals. PRSL B, 275, 1441-8.

5 Secretariat of the Convention on Biological Diversity (2014) Global Biodiversity

6 Outlook 4. Montréal, 155 pages

7

8 Chapman, Colin-C. A., et al. (2014). Safeguarding biodiversity: what is perceived as

Commented [MH2]: Not sure this formatting is right?

9 working, according to the conservation community?. Oryx,Volume?? 1-6.

10 Collar, N. J., and A. T. Juniper. (1992). Dimensions and causes of the parrot conservation crisis. New World parrots in crisis: solutions from conservation biology,

$12 \quad 1-24$.

13 Chapron, Guillaume, Raphaël Arlettaz, and Luigi Boitani. (2010). Why the inaction 14 on biodiversity?. Nature 467.7314, 401-401.

15 Christie, Mike, et al. (2006). Valuing the diversity of biodiversity. Ecological 16 economics $58.2,304-317$.

17 Clavero, Miguel $\underline{M}$, and Emili Garcia-Berthou. (2005). Invasive species are a leading 18 cause of animal extinctions. TRENDS in Ecology and Evolution, 20.3, 110-110.

19 Clout, M. N., and C. R. Veitch. (2002). Turning the tide of biological invasion: the 20 potential for eradicating invasive species." Turning the tide: the eradication of 21 invasive species. IUCN SSC Invasive Species Specialist Group, Gland, Switzerland and 22 Cambridge, UK, 1-3. 
1 Cooper, N., et al. (2008). Macroecology and extinction risk correlates of frogs. Global

2 Ecology and Biogeography 17.2, 211-221.

3 Croxall, J. P., et al. (2012).Seabird conservation status, threats and priority actions: a

4 global assessment." Bird Conservation International 22.01, 1-34.

5 Davidson et al. (2009). Multiple ecological pathways to extinction in mammals.

6 PNAS, 106, 10702-5.

7 Davies, R. G., et al. (2006). Human impacts and the global distribution of extinction

8 risk. Proceedings of the Royal Society B: Biological Sciences, 273.1598, 2127-2133.

9 Fisher, D. O., and I.P.F. Owens. (2004). The comparative method in conservation

10 biology. Trends in Ecology \& Evolution 19.7, 391-398.

11 Gaston, K. J., and T. M. Blackburn. (1995). Birds, body size and the threat of

12 extinction. Philosophical Transactions of the Royal Society B: Biological Sciences.

$13 \quad 347.1320,205-212$.

14 Green, A. J. (1996). Analyses of globally threatened Anatidae in relation to threats,

15 distribution, migration patterns, and habitat use." Conservation Biology, 10.5, 1435-

161445.

17 Hayward, M. W. (2011). Using the IUCN Red List to determine effective conservation 18 strategies. Biodiversity and Conservation, 20.12, 2563-2573.

19 Hoffmann, M., et al. (2010). The impact and shortfall of conservation on the status of the world's vertebrates. Science 330, 1503-1509.

Hoffmann, M. et al. (2015). The difference conservation makes to extinction risk of

22 the world's ungulates. Conservation Biology, Article first published online: 27 APR

2015 DOI: $10.1111 /$ cobi.12519 
1 Johnson, J. B., and K. S. Omland. (2004). Model selection in ecology and evolution.

2 Trends in ecology \& evolution 19.2, 101-108.

3 Kier, G., et al. (2009). A global assessment of endemism and species richness across

4 island and mainland regions. Proceedings of the National Academy of Sciences,

$5 \quad 106.23,9322-9327$.

6 Leader-Williams, N., and H. T. Dublin. (2000). Charismatic megafauna as 'flagship

7 species'. Priorities for the conservation of mammalian diversity: has the panda had its

8 day, 53-81.

9 Lenzen et al. (2012). International trade drives biodiversity threats in developing nations. Nature 486, 109-112 Mace, G. M. "The role of taxonomy in species conservation.(2004). Philosophical Transactions of the Royal Society of London. Series B: Biological Sciences, 359.1444, 711-719.

14 Magnin, G. (1991) Hunting and persecution of migratory birds in the Mediterranean region. In Salathe, T. (ed.) Conserving Migratory Birds: 63-79. International Council for Bird Preservation, Cambridge, UK. conservation targets: current spending and unmet needs. Science, 338.6109, 946949. McClanahan, T. R., et al. (2008). Conservation action in a changing climate. protected area on species threat rates." Conservation Biology, 16.2, 539-543. 
1 Mills, J. H., and T.A. Waite. (2009). Economic prosperity, biodiversity conservation,

2 and the environmental Kuznets curve. Ecological Economics, 68.7, 2087-2095.

3 Owens, I.P.F., and P.M. Bennett. (2000). Ecological basis of extinction risk in birds:

4 habitat loss versus human persecution and introduced predators." Proceedings of

5 the National Academy of Sciences 97.22, 12144-12148.

6 Pimm, S. L., et al. (2014). The biodiversity of species and their rates of extinction,

7 distribution, and protection. Science, 344.6187, 1246752.

8 Purvis, A., et al. (2006). Predicting extinction risk in declining species." Proceedings

9 of the Royal Society of London. Series B: Biological Sciences, 267.1456, 1947-1952.

10 Rodrigues, A.S.L., et al. (2006). The value of the IUCN Red List for conservation."

11 Trends in Ecology \& Evolution, 21.2, 71-76.

12 Rodrigues A.S.L., et al. (2014) Spatially Explicit Trends in the Global Conservation

13 Status of Vertebrates. PLoS ONE 9.11, e113934.doi:10.1371/journal.pone.0113934

14 Salafsky, N., et al. (2008). A standard lexicon for biodiversity conservation: unified

15 classifications of threats and actions." Conservation Biology, 22.4, 897-911.

16 Stein, B.A. et al. (eds.). (2014). Climate-Smart Conservation: Putting Adaptation

17 Principles into Practice. National Wildlife Federation, Washington, DC.

18 http://www.nwf.org/pdf/Climate-Smart-Conservation/NWF-Climate-Smart-

19 Conservation 5-08-14.pdf

20 Veitch, C. R.; Clout, M. N. and Towns, D. R. (eds.) (2011). Island Invasives: Eradication

21 and Management. Proceedings of the International Conference on Island Invasives.

22 Gland, Switzerland: IUCN and Auckland, New Zealand: CBB. xii + 542pp. 
1 Weinzettel et al. (2013). Affluence drives the global displacement of land use. Global

2 Environmental Change, 23, 433-438.

3 Williams D.R. et al. (2012). Bird conservation: global evidence for the effects of

4 interventions. Exeter, Pelagic Publishing.

5 Wolf, S., et al. (2006). Transboundary seabird conservation in an important North

6 American marine ecoregion. Environmental Conservation, 33.04, 294-305.

7 Wright, T.F., et al. (2001). Nest poaching in Neotropical parrots. Conservation

8 Biology, 15.3, 710-720.

9 Zuur, A.F., E.N. Ieno, and C.S. Elphick. (2010). A protocol for data exploration to 10 avoid common statistical problems. Methods in Ecology and Evolution, 1.1, 3-14.

11

12

13

14

15

16

17 
2 Table 1. Types of conservation actions underway that were used in the analysis, plus the variables used to 3 predict conservation action implementation with citations from papers that found these variables to be 4 important in predicting extinction risk.

\begin{tabular}{|c|c|c|}
\hline $\begin{array}{l}\text { Conservation } \\
\text { Actions }\end{array}$ & Definition & $\begin{array}{l}\text { IUCN classification } \\
\text { scheme }\end{array}$ \\
\hline Action Plan & $\begin{array}{l}\text { An action/recovery plan exists for the } \\
\text { species }\end{array}$ & $\begin{array}{l}\text { Research Needed } 2 \\
\text { Conservation Planning }\end{array}$ \\
\hline Monitoring & $\begin{array}{l}\text { The species is subject to a systematic } \\
\text { monitoring scheme }\end{array}$ & $\begin{array}{l}\text { Research Needed } 3 \\
\text { Monitoring }\end{array}$ \\
\hline Protected Area & $\begin{array}{l}\text { The species occurs in at least one } \\
\text { protected area }\end{array}$ & \\
\hline $\begin{array}{l}\text { Invasive Species } \\
\text { Control/Eradication }\end{array}$ & $\begin{array}{l}\text { Invasive alien species which impact the } \\
\text { species are being (or have been) } \\
\text { eradicated, controlled or prevented from } \\
\text { spreading }\end{array}$ & $\begin{array}{l}2.2 \\
\text { Invasive/problematic } \\
\text { species control }\end{array}$ \\
\hline Reintroduction & $\begin{array}{l}\text { The species is being (or has been } \\
\text { successfully) reintroduced or introduced } \\
\text { benignly for conservation purposes }\end{array}$ & $\begin{array}{l}3.3 \text { Species re- } \\
\text { introduction }\end{array}$ \\
\hline Ex Situ & $\begin{array}{l}\text { The species is subject to ex-situ } \\
\text { conservation }\end{array}$ & $\begin{array}{l}\text { 3.4 Ex-situ } \\
\text { conservation }\end{array}$ \\
\hline $\begin{array}{l}\text { Education /awareness- } \\
\text { raising }\end{array}$ & $\begin{array}{l}\text { The species is subject to ongoing (or } \\
\text { recent) education and awareness } \\
\text { programmes }\end{array}$ & $\begin{array}{l}4 \text { Education \& } \\
\text { awareness }\end{array}$ \\
\hline $\begin{array}{l}\text { International } \\
\text { Legislation }\end{array}$ & $\begin{array}{l}\text { Species is listed in international } \\
\text { legislation (e.g. on Appendicies of } \\
\text { CITES and/or CMS and/or its } \\
\text { Agreements and Instruments (ACAP, } \\
\text { AEWA etc) }\end{array}$ & 5 Law \& policy \\
\hline $\begin{array}{l}\text { International } \\
\text { Trade Management }\end{array}$ & $\begin{array}{l}\text { Species is subject to international } \\
\text { management/trade controls }\end{array}$ & $\begin{array}{l}6 \text { Livelihood, economic } \\
\& \text { other incentives }\end{array}$ \\
\hline
\end{tabular}

5

Predictor Variables

Direction of population Trend

IUCN Red List Category

Taxonomic Order

Body Mass

Clutch Size

Generation Length

Landmass Type

Habitat Type

Biogeographic Region

Number of Countries in Species

Range

Size of Breeding Range

Proportion of Range in G20

countries

\section{Citations}

Mace 2004

Gaston and Blackburn 1995; Owens and Bennett 2000;

Fisher and Owens 2004;

Fisher and Owens 2004

Owens and Bennett 2000; Fisher and Owens 2004;

Davies et al 2006

Owens and Bennett 2000

Purvis et al 2000; Cooper et al 2008

Fisher and Owens 2004; Owens and Bennett 2000

Chapron et al 2010 
Proportion of Range in OECD Christie et al 2006

countries

GDP of Countries Within Species McKinney 2002; Davies et al 2006

Range

1

2

3 
1 Table 2. AICc models for conservation actions associated with increasing population trends of Threatened 2 and Near Threatened species.

Population Trend

Education + Int Legislation + Reintroduction + Ex Situ + Invasive Control

Education + Int Legislation + Reintroduction + Ex Situ + Invasive Control + Action Plan

Education + Int Legislation + Reintroduction + Ex Situ +

Invasive Control + Action Plan + Protected Areas

Education + Int Legislation + Reintroduction + Ex Situ +

Invasive Control + Action Plan + Protected Areas + Int Trade

Education + Int Legislation + Reintroduction + Ex Situ +

Invasive Control + Action Plan + Protected Areas + Int Trade +

Monitoring

$\begin{array}{rrrrr}\operatorname{logL} & \mathrm{k} & \mathrm{AICc} & \mathrm{AAI} & \text { wei } \\ & & 513.8 & & \\ -250.90 & 5 & 5 & 0.00 & 0.35 \\ & & 514.1 & & \\ -250.05 & 6 & 7 & 0.32 & 0.30 \\ & & 514.8 & & \\ -249.39 & 7 & 5 & 1.00 & 0.21 \\ & & 516.2 & & \\ -249.09 & 8 & 7 & 2.42 & 0.10 \\ & & & & \\ -249.00 & 9 & 518.1 & & \\ & & & 4.27 & 0.04\end{array}$

3

4 


\section{Figures}

2 Figure 1. Schematic of the data flow.

3 Figure 2. Estimate and 95\% confidence interval of odds ratio of implemented

4 conservation actions associated with increasing population trends of threatened 5 and Near Threatened bird species.

6 